\title{
Development of a trauma-informed substance use and sexual risk reduction intervention for young South African women
}

This article was published in the following Dove Press journal:

Patient Preference and Adherence

Bronwyn Myers ${ }^{1,2}$

Tara Carney ${ }^{1,2}$

Felicia A Browne

Wendee MWechsberg ${ }^{3-6}$

'Alcohol, Tobacco and Other Drug Research Unit, South African Medical Research Council, Tygerberg, Cape Town, South Africa; ${ }^{2}$ Division of Addiction Psychiatry, Psychiatry and Mental Health, University of Cape Town, Cape Town, South Africa; ${ }^{3}$ Substance Use and Gender Research (SUGAR) Program, RTI International, Research Triangle Park, NC, USA; ${ }^{4}$ Department of Public Health, Health Policy and Administration, Gillings School of Global Public Health, The University of North Carolina, Chapel Hill, NC, USA; ${ }^{5}$ Department of Psychology, North Carolina State University, Raleigh, NC, USA; ${ }^{6}$ Department of Psychiatry and Behavioral Medicine, Duke University School of Medicine, Durham, NC, USA
Correspondence: Bronwyn Myers Alcohol, Tobacco and Other Drug Research Unit, South African Medical Research Council, PO Box 19070, Tygerberg, Cape Town 7505, South Africa

Tel +27219380993

Email bmyers@mrc.ac.za
Purpose: To develop a trauma-informed substance use and sexual risk reduction intervention for young South African women at risk of HIV.

Patients and methods: Guided by the ADAPT-ITT framework for intervention development, we selected four focus groups $(n=26)$ to assess the service needs and preferences of traumaexposed young women (aged 18-25 years) who use substances. We used findings to develop a needs-based and contextually appropriate intervention. In addition four focus groups $(n=30)$ were selected to explore potential service users' views of this intervention and recommendations for improving acceptability and appeal. Expert stakeholders were also consulted.

Results: Young women described therapeutic, self-care, and social support needs for coping with traumatic experiences and reducing substance- and sexual-related risks for HIV and further trauma. To address these needs, we expanded the Women's Health Co-Operative (WHC; an evidence-based HIV prevention program) to include trauma-related psychoeducation; cognitivebehavioral strategies for coping with the emotional impact of trauma, stress, and substance use craving; social support strategies; and self-care components to help young women create a life with purpose. This novel and expanded six-session group-based intervention is called the traumainformed WHC. Focus group participants and expert stakeholders viewed the trauma-informed WHC as highly relevant and acceptable. They provided recommendations for modifications to the intervention structure and reformatting of intervention materials to enhance the intervention's appeal and the feasibility of reaching and retaining young women in the program.

Conclusion: Engaging women as potential service users in the process of developing a traumainformed substance use and sexual risk reduction intervention helped identify service needs not commonly addressed in trauma-informed substance use interventions but critical for recovery and local relevance. It also enhanced the acceptability and appeal of the intervention. While potentially acceptable, the trauma-informed WHC requires feasibility testing before establishing its efficacy in a larger trial.

Keywords: participatory approach, ADAPT-ITT, mental health, substance use, HIV

\section{Introduction}

Substance use and exposure to physical and sexual trauma are highly prevalent, intersecting risks for HIV acquisition among young South African women. ${ }^{1-3}$ For example, national studies have shown that $17 \%-45 \%$ of young women report alcohol use, of which $23 \%-36 \%$ engage in heavy episodic drinking. ${ }^{4}$ Studies in South Africa and elsewhere have shown that substances are frequently used to cope with traumatic experiences by helping women avoid or reduce the negative emotions and symptoms associated with trauma. ${ }^{5-7}$ Unfortunately, this maladaptive coping response is associated 
with sexual risk behavior for HIV, such as inconsistent condom use. ${ }^{8}$ Substance use also increases young women's risk of further exposure to physical and sexual trauma, and consequently HIV, as substance use often places women in high-risk environments for assault and because it often exacerbates conflict in relationships. ${ }^{9,10}$

For South Africa to reach its ambitious goal of $63 \%$ reduction in new HIV infections by 2022, ${ }^{11}$ it needs innovative HIV prevention programs that address these intersecting risks for young women among whom new infections are concentrated. ${ }^{12}$ In South Africa, about $17.4 \%$ of young women (20-24 years of age) are living with HIV, ${ }^{12}$ and adolescent girls and young women (AGYW) make up 37\% of all new HIV infections. ${ }^{11}$ Although global and national guidelines for the prevention of HIV infection among AGYW ${ }^{11,13}$ recommend the provision of integrated mental health, substance use, and HIV prevention services, these integrated programs remain scarce. ${ }^{14}$ Recent national campaigns to reduce HIV incidence among AGYW (such as the DREAMS initiative and the She Conquers campaign) have limited focus on the combination of substance use, sexual risk, and past trauma exposure.

As women with experiences of trauma respond more poorly to substance use and sexual risk reduction interventions that are not trauma-informed than women without these experiences, ${ }^{15}$ we expanded the Women's Health Co-Operative (WHC), an evidence-based, women-focused HIV prevention program, ${ }^{16,17}$ to include a focus on trauma and substance use coping. Evidence that trauma-informed substance use interventions significantly reduce trauma-exposed women's substance use, trauma symptoms, and psychological distress guided the choice of this approach. ${ }^{2,18,19}$

The WHC is a two-session intervention, adapted for use in South Africa, ${ }^{20}$ which addresses the intersecting HIV risks of substance use, gender-based violence, and sexual risk behavior. It has shown efficacy for reducing women's substance use and sexual risks for HIV across multiple settings and age groups..$^{20-24}$ It provides women with information on how to reduce substance use risks for interpersonal trauma and HIV, and behavioral skills training for sexual protection, communication for safer sex and conflict resolution. Women develop a personalized action plan that identifies goals for behavior change, strategies to support these goals, and referrals to substance use, sexual health, and other services. ${ }^{23,24}$ However, no adaptations in South Africa have addressed the additional needs for women with past and current trauma.

This study describes the expansion of the WHC into a new trauma-informed substance use and sexual risk reduction intervention (trauma-informed WHC). As young women's initiation and engagement in health services is influenced by whether they perceive a program to be responsive to their needs and preferences, ${ }^{14,25}$ we used the ADAPT-ITT framework, a rigorous process for adapting evidence-based HIV interventions, ${ }^{26}$ to ensure that young women's service needs and preferences were incorporated into the intervention design.

The framework specifies eight steps for adapting interventions to new priorities. The first step involves the assessment of service users' needs, which guides decisionmaking about the modifications that are needed (step two). The third step involves intervention adaptation and initial administration of the program to potential service users to identify where the intervention requires revision to improve its relevance and acceptability. Thereafter, intervention production occurs in which further adaptations are made (step four) and this revised intervention is reviewed by topical experts (step five). Steps six through eight involve integrating all feedback into a final version of the intervention, training staff to deliver the intervention, and feasibility testing of the intervention. ${ }^{26}$

This paper reviews the process of developing the traumainformed WHC. Specific aims are to describe 1) young women's needs and preferences for a trauma-informed substance use and sexual risk reduction intervention and 2) their perceptions of the acceptability of the intervention and recommendations for further modification.

\section{Methods}

Between August 2015 and February 2016, we used the first six ADAPT-ITT steps to expand the WHC into a traumainformed substance use and sexual risk reduction intervention (see Table 1 for an overview of the intervention development phases) in preparation for the training and feasibility testing (the final ADAPT-ITT steps). The South African Medical Research Council and RTI International provided ethical approval for this study.

\section{Participants and procedures}

To assess young women's intervention needs (step 1), we conducted four focus group discussions (FGDs) with 26 women recruited from two low-income Cape Town communities with high levels of sexual and physical violence, and substance use. Two groups comprised Black African women (six and eight participants, respectively) and two comprised Colored (of mixed race ancestry) women (with seven and five participants, respectively). The communities 
Table I Phases of developing the trauma-informed WHC

\begin{tabular}{|c|c|c|}
\hline ADAPT-ITT step & Method & Intervention modification \\
\hline Step I: Assessment & $\begin{array}{l}\text { Four focus groups }(n=26) \text { with young women to assess service } \\
\text { needs and preferences. }\end{array}$ & Original WHC as foundation \\
\hline Step 2: Decisions & $\begin{array}{l}\text { Used assessment findings to inform decisions about intervention } \\
\text { development. Involved in the synthesis of materials from other } \\
\text { studies and development of new materials for this population. }\end{array}$ & Version I \\
\hline Step 3: Administration & $\begin{array}{l}\text { Demonstrate the new trauma-informed WHC in four focus } \\
\text { groups of young women }(n=30) \text {. }\end{array}$ & Version I \\
\hline Step 4: Production & $\begin{array}{l}\text { Use findings to modify intervention materials and structure, } \\
\text { producing next version of the intervention. }\end{array}$ & Version 2 \\
\hline $\begin{array}{l}\text { Steps } 5 \text { and 6: Topical } \\
\text { experts and integration }\end{array}$ & $\begin{array}{l}\text { Obtain } \mathrm{CAB} \text { stakeholder feedback. Use findings to further } \\
\text { revise intervention and intervention implementation plans. }\end{array}$ & Version 3 \\
\hline
\end{tabular}

Abbreviations: CAB, community advisory board; WHC, Women's Health Co-Operative.

from which we recruited participants are ethnically distinct from each other, with one comprised predominantly Black African isiXhosa-speaking individuals, and the other comprised predominantly Colored, Afrikaans-speaking individuals. These community and language differences were the main reasons for distinguishing groups along ethnic lines. Field staff approached potential participants in community settings frequented by young women, described the study, and requested verbal consent for eligibility screening. Women were eligible if they were between 18 and 25 years of age, lived in the target communities, and reported lifetime sexual or physical abuse, the use of at least two substances weekly for the past 3 months, condom-less sex in the past 3 months, and willingness to participate in group discussions. Given the pervasiveness of regular, heavy episodic drinking in this region, ${ }^{4}$ we recruited women who used at least two substances to ensure that the sample included women who used illicit drugs. Of the 44 women screened, 9 were ineligible (21\%). The 35 eligible women who were interested in study participation were invited to an FGD, of which 26 (73\%) came. Alcohol, cannabis, and methamphetamine were the most commonly reported substances used by eligible women - this is keeping with patterns of substance use in this region. ${ }^{14,25}$ Most women reported multiple exposures to sexual and physical abuse, predominantly by family members during childhood, but intimate partner violence was also commonly reported. The nine eligible women who did not participate in the group had initially agreed to participate but were not locatable in the community due to their transient living circumstances. Prior to FGDs, women were rescreened to confirm their eligibility, and written informed consent for participation was obtained. Two experienced $\mathrm{PhD}$-level qualitative researchers, both with extensive experience in group dynamics and intervention adaptation, facilitated the discussions. Field staff took notes and assisted with translations into local languages if required. Facilitators used a semi-structured discussion guide comprising open-ended questions and probes that were used to elicit participants' opinions about trauma- and substance use-related service needs and preferences for these services as well as barriers and facilitators to women's use of available services. The discussion guide evolved with each group discussion as participants provided new information that raised additional questions for the research team. Questions included, "How is substance use related to experiences of violence and abuse?", "To what extent do young women need help in coping with experiences of abuse and violence?", "If we were to develop a counselling programme for women who have had experiences of abuse and who use substances, what would you like this program to look like?", among others. FGDs took place in a private room at an established study site and lasted up to 2 hours. Discussions were audio-recorded and transcribed verbatim. Participants were provided with refreshments, a grocery voucher for their time, referrals to substance use and trauma services, and transport. We used findings from this phase to guide decisions about the expansion of the WHC (step 2).

Next, we showed the first version of the intervention to 30 women in four FGDs (two groups of eight Black African women and two groups of seven Colored women) and elicited their responses to this intervention (step 3). We used the same recruitment procedures and eligibility criteria described earlier. Of the 39 women screened, only 1 was ineligible (3\%). The 38 eligible women who were interested in study participation were invited to an FGD, of which only 30 (79\%) came. Facilitators used a semi-structured discussion guide to elicit participants' views about the acceptability of the intervention and its most salient aspects, components that required modification, and recommendations for improvement. Questions included, "What are your thoughts about 
the proposed intervention?", "How well do you think the intervention will work in this community?", "How interested do you think young women like yourself would be to participate in this program?", among others. All groups were facilitated and recorded using the same procedures as those described earlier. We used the feedback from these groups to refine the intervention (step 4).

We presented the refined intervention to our community advisory board (CAB) and asked members, as topical experts, to comment on necessary modifications. Active since 2005, this $\mathrm{CAB}$ includes representatives from nongovernmental organizations, community-based organizations, government, academic institutions, and communities where the intervention will be tested once the adaptation process is complete. These topical experts were knowledgeable and experienced in the provision of substance use treatment services for women; the provision of HIV prevention, treatment and care in primary care settings; gender-based violence prevention; psychological treatments for substance use disorders; psychological treatments for trauma and post-traumatic stress disorder; and community development. Their feedback was used to make final adjustments to the intervention materials (step 5). Finally, we integrated all findings and feedback into a final iteration of the intervention (step 6) ready for staff training and initial feasibility testing (steps 7 and 8 , respectively).

\section{Analysis}

We used the framework approach ${ }^{27}$ to analyze FGD data. This five-stage approach allows themes to be explored in relation to research questions and for new themes to emerge from the data. The first three stages, "familiarization" with the data, "identification of a thematic framework", and "indexing" (or coding) of data are similar to other forms of qualitative analysis. The fourth stage, "charting", involves retrieving the coded data and creating summaries of each interviewee's talk on each theme. The final stage, "mapping and interpretation" of data, involves the research team using the charts to interpret the entire data set and connect with research objectives. These stages are interconnected, allowing the researchers to move back and forth across the data until a coherent account emerges. Unlike other approaches to qualitative analysis, these stages give visibility to the analysis process. Ensuring data analysis is explicitly described enhances the credibility of the findings.

More specifically, two PhD-level study staff with considerable experience in qualitative analysis read the transcripts, identified emerging themes, and developed a coding frame (codebook), which was discussed and agreed upon as a team. After agreement was reached, they used NVivo version 11 to independently code the transcripts, meeting regularly to compare notes and resolve coding differences. Differences in coding were resolved by discussion with the first author being available to resolve discrepancies when consensus could not be reached by discussion. This third person was not needed to break coding ties. Inter-coder reliability was good, with a Kappa score of 0.87 .

\section{Results \\ Assessment of intervention needs and preferences}

Three themes emerged from each of the FGDs, regardless of the ethnic background of the participants. The first theme describes how participants use substances to cope with the emotional impact of past trauma and to avoid current problems in their lives. The second theme describes participants' desire for change and factors that may hinder change. The third theme describes participants' preferences for the content, format, and structure of a trauma-informed substance use and sexual risk reduction program. The sections that follow are organized according to these themes, with some examples of participants' responses to illustrate these themes.

\section{Substance use coping for past trauma and current problems}

All participants spoke about unresolved experiences of physical and sexual abuse. They feared "not being taken seriously" so they "just sit with it and don't tell anybody". Although some knew of trauma counseling programs, they thought these services were not helpful. Many women spoke of using substances to cope with shame, embarrassment, and other emotions arising from these experiences. They described using substances to "feel nothing", "comfort" themselves, or "forget" the trauma:

"I started using drugs after I was raped. I use drugs just to forget, have some fun and pretend like that never happened."

[FG 1]

"Drugs takes away that embarrassed feeling ... you feel

like it comforts you." [FG 4]

Most participants acknowledged that this coping mechanism introduced many other problems to their lives. Women in all groups spoke of young women "selling their bodies" for substances, reflecting that "you do what you need to do to get drugs". As one woman commented 
"If they don't have money, they go and sleep with those guys to get the drug. So it spreads HIV." [FG 2]

Similarly, there was consensus that substance use increased women's risk of further trauma. Participants commented how men "take advantage of women when they are drunk or drugged and have sex with us" and how substance use fueled violence in relationships:

"She drinks (alcohol) and her boyfriend uses drugs.

Whenever he comes back in the house they fight ... there is always violence. When they are sober they don't know any fights.” [FG 2]

Despite appreciating that substance use provided only a temporary solution to their problems, participants described feeling compelled to continue using substances as they lacked alternative mechanisms for coping with the emotional impact of trauma:

"Later the problems are still there. From the start, it just goes back to the same thing over and over." [FG 3]

"Sometimes you want to stop all this drinking and drugs, you want to focus on life, but still you keep on thinking about those things ... that you were abused. It comes back. It stops you from going forward.” [FG 1]

For these women, substance use was also their main strategy for dealing with current stressors, problems, and "frustration":

"If my daily problems get too big or too many, then I go do drugs." [FG 4]

"They have problems at home and they don't know how

to fix them, so they do drugs to escape." [FG 1]

Regardless of their background, they all wanted tools to help them with "new ways of coping" with everyday problems and conflict in their lives.

\section{Desire for a different life and barriers to change}

In all the groups, discussions reflected participants' desire for a different life and "really wanting to be helped" and wanting to "be a better person":

"It is hard to talk about these issues - but we want to feel relief ... why should I keep it inside. If I talk it out it is out of my system." [FG 2]

Although participants reported being "tired of using drug to cope and tired of doing things that you were doing to get smoke (drugs)", they described not knowing "how to stop." Fear that their lives would be unmanageable if they did not use substances was a barrier to change. Participants were particularly concerned about managing substance-related cravings:

"Sometimes the cravings make it difficult to stop. That one packet makes you feel for more." [FG 3]

Participants identified a lack of emotional support as a barrier to change. There was consensus in the groups that family and community support for change was rare. Most reflected that their families "had turned their backs" on them:

"When I need support, they don't give me time. I need support because I don't know how I am going to stop this thing." [FG 4]

"The support you need is that someone to talk to. Someone to call you and to support you to stop what you are doing ... that someone who is reminding me 'hey how about you stop, don't you want to change your life." [FG 1]

\section{Preferences for intervention content, format, and structure}

When asked about their preferences for a trauma-informed substance use and sexual risk reduction intervention, most participants said they wanted an intensive half-day program that included multiple appointments each week, noting that this would "hold us and support us":

"Everyday, because we are sitting around doing nothing.

Maybe we get in there at eight o'clock to maybe to one

o'clock get out because we have children too." [FG 2]

In addition to therapeutic content, participants asked for program content to help them reach their life goals and create a meaningful life. For many, these goals included "being a better mother" and "taking care of my family" and "being able to provide". As such, they requested assistance with parenting, budgeting, and employment skills. They also wished to learn more about exercise and nutrition to help them take care of themselves and their families. In terms of the intervention format, they asked for the inclusion of "activities" and opportunities for skills rehearsal and not just a didactic approach to content delivery:

"It would help when you go to a program, you don't sit and talk all day. Like get up and do something." [FG 3]

In addition, participants agreed that the intervention should be group-based rather than individual-based. Although they recognized that some young women may initially find it 
"hard to open up" in a group, they thought that this approach could lead to women supporting each other more:

"If we have group sessions, we will keep supporting each other ... that's where a person will feel free.” [FG 4]

Several participants thought community-based case management activities, or "home visits", could also help young women feel supported. They thought that these home visits would help women "know all these people care for me".

\section{Adaptation decisions}

Based on these findings, we retained the WHC's core content addressing substance use and its intersection with violence and HIV risk, HIV prevention strategies (including condom mastery and sexual negotiation skills), and violence prevention strategies (including conflict resolution skills). We integrated content on common coping responses to trauma and ways of managing these responses in relation to sex risk that was used in a previous adaptation of the WHC that focused on trauma among women incarcerated in US prisons. ${ }^{28}$ We also added new cognitive-behavioral therapy (CBT) material on identifying and managing emotional and other triggers for substance use through mindfulness practice, thought stopping techniques, and other emotional regulation and coping strategies. We included these new components as they have been shown to reduce trauma-related internal triggers for substance use. ${ }^{29}$ These new components were accompanied by skills rehearsal activities.

In addition to this therapeutic content, we incorporated modules on nutrition, exercise, budgeting, and parenting into the program. The nutrition material, used by a previous study, ${ }^{23}$ taught women about the basic food groups, healthy food preparation, and how to develop a menu on a limited budget. The intervention also included information on exercise which we expanded to include more information on the benefits of exercise for coping with stress and emotions, demonstrations, and opportunities for women to practice these activities. The parenting module and job skills content was adapted from a previous iteration of the WHC with pregnant women ${ }^{21}$ and included information on parenting styles, effective discipline, building a resume, seeking employment, and interview skills.

These additions expanded the WHC from 4 modules delivered over 2 sessions into 12 modules delivered over 6 sessions. We designed the program to be delivered in groups and included case management activities to increase women's support for change.

\section{Initial administration}

Two themes emerged from the FGDs after the initial demonstration of the intervention. The first theme referred to the acceptability of the intervention content and the second theme referred to recommendations for program delivery.

\section{Acceptability of the intervention}

Across the groups, participants agreed that the intervention content was acceptable, commenting that it is "good because it's going to help us" and "give us a beginning for a good future."

The participants thought the program content was sufficiently comprehensive and "enough" to address their needs. They did not want any program content to be removed, remarking that all the modules were potentially beneficial:

"We need all this information to stop the wrong things."

[FG 1]

Participants did, however, recommend rearranging the intervention modules to ensure that the components they considered key (substance use coping, trauma, and sexual safety) were presented early in the program:

"And I like the part of resolving the trauma. That's the thing that makes us like smoke (drugs). You should bring it (the session) up to the second day because it is the right thing to talk about." [FG 3]

Participants also asked for a participant information booklet that summarized the key content of each session. They thought that would help them "remember" the program content and increase impact:

"And you can practice it (skills) at home because now you have some ideas and something to show you how if you can't remember." [FG 4]

\section{Recommendations for program format and structure}

The participants had clear views on when the intervention should be delivered to reach and engage young women. They recommended offering the program on Tuesdays, Wednesdays, and Fridays. They thought women would be inattentive on Mondays, as they might be recovering from the weekend's substance use. In contrast, they thought program contact on a Friday would help avoid substance use over the weekend:

"On Mondays no ... you're coming from the weekend and
you are babelas (hungover) ... your brain is not working."

[FG 2] 
When asked about the duration of the modules, generally participants thought the duration was acceptable, provided that the content was exciting enough to keep women engaged and they were given sufficient breaks:

"It mustn’t be boring, it must have fun things to do." [FG 4]

Participants also commented on the formatting of the intervention materials. All the groups preferred materials in English but thought the language should be simplified to reach young women with varying levels of education:

"Not that big word English. Simplify the language ...

everyone would then understand." [FG 3]

They did, however, like the home visits and the group format, noting that this format may help young women "unite for change" and could lead to the development of peer support networks in their communities.

\section{Production}

Based on participants' suggestions, we reformatted the intervention to include more breaks to help women remain attentive. We also reordered the modules so that the most critical information (substance use, coping with trauma, and sexual safety) is covered in the first week of the program. In addition, we refined the intervention materials to enhance their appeal and comprehensibility. These modifications included simplifying the language used, reducing the amount of text, and adding more visuals. Additional skills practice activities were also added to each module to keep women engaged and encourage mastery of new skills. For example, we added audio clips of mindfulness meditation exercises that women practiced in the groups. Based on participants' recommendations for handouts, the project team developed a participant handbook that summarized the core content of each module, included activities for skills rehearsal at home, and summarized their personal action plan and goals for change. Together, these modifications produced the second version of the trauma-informed WHC.

\section{Topical experts' commentary and integration of feedback}

Next, we asked CAB members (and other trauma and substance use service providers) to review the second version of the intervention, the participant handbook, and comment on potential implementation concerns such as intervention delivery agents and referral pathways for linking young women to further services if needed. Based on their suggestions, we expanded our community referral and resource guide to include more substance use and trauma service providers. Topical experts also recommended the use of registered psychological counselors, trained in trauma debriefing, for intervention delivery and the provision of regular debriefing to prevent burnout. We used these recommendations to develop a counselor training and supervision plan. Experts also suggested some minor revisions to enhance the appeal of the intervention materials. All this feedback was integrated into a third version of the trauma-informed WHC that is ready for feasibility testing. Table 2 presents an overview of the components of this final version of the intervention and their origin.

\section{Discussion}

Although global guidelines for the prevention of HIV infection among AGYW recommend the provision of integrated trauma, substance use, and sexual risk reduction services, ${ }^{13}$ these comprehensive programs are rare. This paper describes the systematic development of a novel trauma-informed substance use and sexual risk reduction intervention tailored to the service needs and preferences of young South African women.

In this formative study, participants expressed many unmet mental health and substance use needs and desired change. In keeping with other studies, ${ }^{8,18,32}$ young women doubted the utility of available trauma and substance use services. Yet, they were willing to attend new trauma-informed substance use programs if they were compatible with their service needs. Trauma-exposed young women described a range of unmet informational, therapeutic, self-care, and social support needs that they wished to have addressed by new programs. They requested a better understanding of women's emotional and behavioral responses to trauma and alternative strategies to substance use coping. Specific therapeutic needs were related to managing emotional triggers for substance use, coping with stress, conflict resolution, and sexual safety and violence prevention. They also identified social support and self-care needs that they considered key to building a life with purpose and maintaining change. For these young women, a purposeful life was one in which they could provide and care for their children. This is congruent with African cultural values that emphasize the importance of children. ${ }^{24}$ Addressing these social support and self-care needs may be particularly important in this context, given evidence that limited social support and a lack of purpose affect young South African women's motivation for change 
Table 2 Overview of the trauma-informed WHC program

\begin{tabular}{|c|c|c|}
\hline Tuesday & Wednesday & Friday \\
\hline $\begin{array}{l}\text { Session I. Module I. Where are you in your life: } \\
\text { - Risk vs power } \\
\text { - Substance use and the value of treatment }{ }^{\mathrm{a}} \\
\text { - The importance of social support: Sister to } \\
\text { Sister } \\
\text { - Sisterhood pledge } \\
\text { Session I. Module } 2 \text {. Self-care for recovery: } \\
\text { - What is self-care? } \\
\text { - Exercise for recovery } \\
\text { - Assessing your own }{ }^{\mathrm{b}} \text { exercise habits }\end{array}$ & $\begin{array}{l}\text { Session 2. Module 3. Coping with trauma: } \\
\text { - Types of trauma } \\
\text { - Responses to trauma } \\
\text { - Substance use coping } \\
\text { - More adaptive coping }{ }^{\mathrm{b}} \text { strategies (practice) }^{\mathrm{c}} \\
\text { - Social support } \\
\text { Session } 2 \text {. Module } 4 \text {. Mindfulness for coping: } \\
\text { - What is mindfulness? }{ }^{\mathrm{b}} \\
\text { - Help with bad feelings }{ }^{\mathrm{b}} \\
\text { - Techniques } \\
\text { - Practice }\end{array}$ & $\begin{array}{l}\text { Session 3. Module 5. Sex, STIs, and HIV: } \\
\text { - Substance use, violence, and sexual risk } \\
\text { - Men's and women's bodies }{ }^{\mathrm{a}} \\
\text { - HIV and STIs }{ }^{\mathrm{a}} \\
\text { - Knowing your HIV status }{ }^{\mathrm{a}} \\
\text { Session } 3 \text {. Module 6. Sexual safety: } \\
\text { - Male and female condoms }{ }^{\mathrm{a}} \\
\text { - Sexual negotiation } \\
\text { - A substance use, sexual risk and violence } \\
\text { safety plan }\end{array}$ \\
\hline $\begin{array}{l}\text { Session 4. Module 7. Caring for others: } \\
\text { - How substance use and trauma impacts } \\
\text { caring for others }^{b} \\
\text { - Effective parenting styles }{ }^{d} \\
\text { - Parenting and discipline tips }{ }^{d} \\
\text { - The importance of social support } \\
\text { Session 4. Module } 8 \text {. Nurturing yourself: } \\
\text { - Value of nutrition for recovery } \\
\text { - What is good nutrition } \\
\text { - Reviewing eating habits } \\
\text { - Principles of healthy eating }\end{array}$ & $\begin{array}{l}\text { Session 5. Module 9. Self-care through } \\
\text { exercise: } \\
\text { - Types of exercise }{ }^{b} \\
\text { - Demonstration and practice }{ }^{b} \\
\text { - Plans for exercise }{ }^{a} \\
\text { - Social support for exercise } \\
\text { Session } 5 \text {. Module } 10 \text {. Nutrition on a budget: } \\
\text { - Healthy eating on a budget - some tips }{ }^{b} \\
\text { - Shopping wisely } \\
\text { - Working in a budget } \\
\text { - Reading food labels }\end{array}$ & $\begin{array}{l}\text { Session 6. Module II. Violence prevention: } \\
\text { - Substance use, violence, and } \text { conflict }^{\mathrm{b}} \\
\text { - Conflict resolution skills } \\
\text { - Violence prevention strategies } \\
\text { - Social support for violence prevention }{ }^{\mathrm{b}} \\
\text { Session 6. Module } 12 \text {. Moving on: } \\
\text { - CV development } \\
\text { - Job interview skills } \\
\text { - Future plans } \\
\text { - Continued care support } \\
\text { Personalized action plan and case management }\end{array}$ \\
\hline
\end{tabular}

Notes: ${ }^{a} \mathrm{WHC}$; ${ }^{b} \mathrm{New}$ material; ${ }^{\mathrm{W}} \mathrm{WHC}$ incarcerated women; ${ }^{\mathrm{d}} \mathrm{HOOP}$ study.

Abbreviations: STIs, sexually transmitted infections; WHC, Women's Health Co-Operative.

and service utilization. ${ }^{18}$ There is also emerging evidence that a meaningful life is associated with better post-trauma recovery. ${ }^{30}$ Trauma-exposed women may face additional obstacles to changing their substance use that were not evident in these FGDs. Future studies should explore the full range of possible barriers to change to ensure that interventions target these factors.

Together, this information guided the development of a contextually appropriate trauma-informed substance use and sexual risk reduction intervention tailored to young women's therapeutic, self-care, and social support needs. For the therapeutic content, we retained the core elements of the WHC known to be effective for reducing sexual risk behavior, ${ }^{23,24}$ while adding trauma-related psychoeducation and CBT strategies for identifying emotional triggers for substance use, emotional regulation, adaptive coping and problem-solving, and managing cravings. These are common elements of evidence-based, trauma-informed substance use treatments. ${ }^{2}$ To address self-care needs, we added parenting, budgeting, nutrition, exercise, and employment modules that have been used in other South African studies. ${ }^{20-24}$ To address social support needs, we designed this as a group-based intervention, with the hope that groups would evolve into peer support networks, as has happened elsewhere. ${ }^{31}$ This intervention is novel in that it comprehensively addresses young women's service needs. We are not aware of any other trauma-informed substance use interventions that augment therapeutic content with self-care strategies to support the creation of purpose.

Findings suggest that this novel intervention is probably acceptable to young trauma-exposed South African women who use substances. Feedback about the intervention was positive and helped guide modifications to the intervention structure and format for optimizing acceptability and feasibility of implementation. Despite our concerns about intervention length, young women wanted to retain all the modules as they viewed the content as highly relevant to their needs. However, they recommended some changes to the structure of the intervention and formatting of the intervention materials to enhance its appeal and the likelihood of keeping young women engaged in the program. CAB stakeholders made similar suggestions for intervention refinements. In addition, they suggested ways of facilitating intervention delivery and young women's linkage to continuing care. Together, these findings highlight the value of a participatory approach to intervention development. This method allowed us to incorporate the views and preferences of potential service users and local stakeholders' guidance into the design of the intervention, improving the acceptability and feasibility of the intervention in the local context.

There are two main limitations to this formative study. First, as the sample was small and limited to two communities, 
participants may not have been representative of all traumaexposed young women who use substances in the Western Cape. However, young women's service needs were in line with the global literature on trauma-informed substance abuse treatment. In addition, young women's suggestions for refining the structure and format of the intervention were congruent with CAB stakeholders' opinions. These factors enhance our confidence in the relevance of these findings. Second, due to the qualitative and exploratory nature of this study, we were unable to assess level of treatment need and barriers to treatment attendance in this population. We plan to address these questions in a feasibility test of the traumaWHC which will assess the demand for the program, its uptake, and barriers to program completion.

\section{Conclusion}

A systematic participatory approach was used to develop a trauma-informed comprehensive HIV prevention intervention for young trauma-exposed South African women who use substances. While we incorporated essential components from the WHC and other studies to adapt this intervention, it is unique as it synthesizes these components and new material into a more encompassing program for young South African women. Engaging potential service users in this process helped us capture service needs that are not commonly addressed in trauma-informed substance use interventions but are critical for recovery and contextually important. It also enhanced the acceptability and appeal of the intervention, which may facilitate efforts to reach and engage young women in this program. As the final step in the development process, this novel intervention requires feasibility testing before its efficacy can be examined. If shown to be feasible and efficacious, this intervention may reduce risk of HIV among this highly vulnerable yet underserved population.

\section{Acknowledgments}

Research reported in this publication was supported by the Eunice Kennedy Shriver National Institute of Child Health and Human Development of the National Institutes of Health under Award Number R21HD082866 and by the South African Medical Research Council and National Research Foundation. The content is solely the responsibility of the authors and does not necessarily represent the official views of the National Institutes of Health.

\section{Disclosure}

The authors report no conflicts of interest in this work.

\section{References}

1. Pitpitan EV, Kalichman SC, Eaton LA, Sikkema KJ, Watt MH, Skinner D. Gender-based violence and HIV sexual risk behavior: alcohol use and mental health problems as mediators among women in drinking venues, Cape Town. Soc Sci Med. 2012;75(8):1417-1425.

2. Gilbert L, Raj A, Hien D, Stockman J, Terlikbayeva A, Wyatt G. Targeting the SAVA (substance abuse, violence, and AIDS) syndemic among women and girls: a global review of epidemiology and integrated interventions. J Acquir Immune Defic Syndr. 2015;69 Suppl 2: S118-S127.

3. Kaminer D, Grimsrud A, Myer L, Stein DJ, Williams DR. Risk for posttraumatic stress disorder associated with different forms of interpersonal violence in South Africa. Soc Sci Med. 2008;67(10):1589-1595.

4. Ramsoomar L, Morojele NK. Trends in alcohol prevalence, age of initiation and association with alcohol-related harm among South African youth: implications for policy. S Afr Med J. 2012;102(7):609-612.

5. Berg MK, Hobkirk AL, Joska JA, Meade CS. The role of substance use coping in the relation between childhood sexual abuse and depression among methamphetamine users in South Africa. Psychol Trauma. 2017;9(4):493-499.

6. Hobkirk AL, Watt MH, Myers B, Skinner D, Meade CS. A qualitative study of methamphetamine initiation in Cape Town, South Africa. Int $J$ Drug Policy. 2016;30:99-106.

7. Ullman SE, Relyea M, Peter-Hagene L, Vasquez AL. Trauma histories, substance use coping, PTSD, and problem substance use among sexual assault victims. Addict Behav. 2013;38(6):2219-2223.

8. Wechsberg WM, Jones HE, Zule WA, et al. Methamphetamine ("tik") use and its association with condom use among out-of-school females in Cape Town, South Africa. Am J Drug Alcohol Abuse. 2010; 36(4):208-213.

9. Rivera PM, Bray BC, Guastaferro K, Kugler K, Noll JG. Linking patterns of substance use with sexual risk-taking among female adolescents with and without histories of maltreatment. J Adolesc Health. 2018;62(5):556-562.

10. Jewkes RK, Dunkle K, Nduna M, Shai N. Intimate partner violence, relationship power inequity, and incidence of HIV infection in young women in South Africa: a cohort study. Lancet. 2010;376(9734):41-48.

11. The South African National AIDS Council (SANAC). Let Our Actions Count: South Africa's National Strategic Plan for HIV, TB, and STIs. 2017-2022. Pretoria: SANAC; 2017. Available from: https://www. health-e.org.za/wp-content/uploads/2017/05/SANAC_NSP_Booklet_ V2-07.pdf. Accessed May 15, 2018.

12. Shisana O, Rehle T, Simbayi LC. South African National HIV Prevalence, Incidence, Behaviour and Communication Survey, 2008. A Turning Tide among Teenagers? Cape Town: Human Sciences Research Council; 2011. Available from: https://www.unicef.org/southafrica/ SAF_resources_hivprev08.pdf. Accessed May 16, 2018.

13. UNAIDS. Guidance on HIV Prevention among Adolescent Girls and Young Women. Putting HIV Prevention among Adolescent Girls and Young Women on the Fast-Track and Engaging Men and Boys. Vienna: UNAIDS; 2016. Available from: http://www.unaids.org/sites/ default/files/media_asset/UNAIDS_HIV_prevention_among_adolescent_girls_and_young_women.pdf. Accessed May 8, 2018.

14. Myers B, Carney T, Wechsberg WM. "Not on the agenda": a qualitative study of influences on health services use among poor young women who use drugs in Cape Town, South Africa. Int J Drug Policy. 2016;30:52-58.

15. Reed E, Myers B, Novak SP, Browne FA, Wechsberg WM. Experiences of violence and association with decreased drug abstinence among women in Cape Town, South Africa. AIDS Behav. 2015;19(1):192-198.

16. Lyles CM, Kay LS, Crepaz N, et al. Best-evidence interventions: findings from a systematic review of HIV behavioral interventions for US populations at high risk, 2000-2004. Am J Public Health 2007;97: 133-143.

17. Cottler LB, Leukefeld C, Hoffman J, et al. Effectiveness of HIV risk reduction initiatives among out-of-treatment non-injection drug users. J Psychoactive Drugs. 1998;30(3):279-290. 
18. Torchalla I, Nosen L, Rostam H, Allen P. Integrated treatment programs for individuals with concurrent substance use disorders and trauma experiences: a systematic review and meta-analysis. $J$ Subst Abuse Treat. 2012;42(1):65-77.

19. Roberts NP, Roberts PA, Jones N, Bisson JI. Psychological interventions for post-traumatic stress disorder and comorbid substance use disorder: a systematic review and meta-analysis. Clin Psychol Rev. 2015;38: 25-38.

20. Wechsberg WM, Luseno WK, Lam WK, Parry CD, Morojele NK. Substance use, sexual risk, and violence: HIV prevention intervention with sex workers in Pretoria. AIDS Behav. 2006;10(2):131-137.

21. Jones HE, Myers B, O'Grady KE, GebhardtS, Theron GB, Wechsberg WM. Initial feasibility and acceptability of a comprehensive intervention for methamphetamine-using pregnant women in South Africa. Psychiatry J. 2014;2014:1-8.

22. Wechsberg WM, Zule WA, El-Bassel N, et al. The male factor: outcomes from a cluster randomized field experiment with a couples-based HIV prevention intervention in a South African township. Drug Alcohol Depend. 2016;161:307-315.

23. Wechsberg WM, Jewkes R, Novak SP, et al. A brief intervention for drug use, sexual risk behaviours and violence prevention with vulnerable women in South Africa: a randomised trial of the Women's Health CoOp. BMJ Open. 2013;3(5):e002622.

24. Wechsberg WM, El-Bassel N, Carney T, et al. Adapting an evidencebased HIV behavioural intervention for South African couples. Subst Abuse Treat Prev Policy. 2015;10(6):6.
25. Myers B, Kline TL, Doherty IA, Carney T, Wechsberg WM. Perceived need for substance use treatment among young women from disadvantaged communities in Cape Town, South Africa. BMC Psychiatry. 2014;14:100.

26. Wingood GM, Diclemente RJ. The ADAPT-ITT model: a novel method of adapting evidence-based HIV Interventions. J Acquir Immune Defic Syndr. 2008;47 Suppl 1:S40-S46.

27. Ritchie J, Spencer L, Burgess RG. Qualitative data analysis for applied policy research. In: Bryman A and Burgess RG, editors. Analysing Qualitative Data. London: Routledge; 1994:173-194.

28. Johnson JE, Peabody ME, Wechsberg WM, Rosen RK, Fernandes K, Zlotnick C. Feasibility of an HIV/STI risk reduction program for incarcerated women who have experienced interpersonal violence. J Interpers Violence. 2015;30(18):3244-3266.

29. Garland EL, Roberts-Lewis A, Tronnier CD, Graves R, Kelley K. Mindfulness-oriented recovery enhancement versus CBT for cooccurring substance dependence, traumatic stress, and psychiatric disorders: proximal outcomes from a pragmatic randomized trial. Behav Res Ther. 2016;77:7-16.

30. Linley PA, Joseph S. Meaning in life and posttraumatic growth. J Loss Trauma. 2011;16(2):150-159.

31. Reed E, Emanuel AN, Myers B, Johnson K, Wechsberg WM. The relevance of social contexts and social action in reducing substance use and victimization among women participating in an HIV prevention intervention in Cape Town, South Africa. Subst Abuse Rehabil. $2013 ; 4: 55-64$
Patient Preference and Adherence

\section{Publish your work in this journal}

Patient Preference and Adherence is an international, peer-reviewed, open access journal that focuses on the growing importance of patient preference and adherence throughout the therapeutic continuum. Patient satisfaction, acceptability, quality of life, compliance, persistence and their role in developing new therapeutic modalities and compounds to optimize

\section{Dovepress}

clinical outcomes for existing disease states are major areas of interest for the journal. This journal has been accepted for indexing on PubMed Central. The manuscript management system is completely online and includes a very quick and fair peer-review system, which is all easy to use. Visit http://www. dovepress.com/testimonials.php to read real quotes from published authors. 